\title{
¿Ruralidad sin agricultura?
}

Patricia Arias •

Este libro reúne los trabajos emanados de un proyecto colectivo de investigación de cuatro años de duración —de 2001 a 2004- realizados en tres localidades rurales donde participaron, junto a investigadores de El Colegio de México, estudiantes de licenciatura, maestría y doctorado de Economía y Sociología de la misma institución. Es decir, fue una investigación que sirvió como campo de entrenamiento para nuevas generaciones de investigadores, conjunción para todos beneficiosa pero muchas veces difícil de realizar. Más tarde, Kirsten Appendini y Gabriela Torres-Mazuera se dieron a la tarea de reunir y convertir en libro los diversos trabajos a partir de una idea central que fue el eje de las investigaciones: la crisis, al parecer irremediable, de la producción agrícola tradicional en las comunidades rurales.

Desde el inicio, las dos editoras, que son también coautoras de esta reciente publicación de El Colegio de México, van a lanzar tres ideas y argumentos que, aunque certeros, suelen todavía suscitar resistencias. En primer lugar, inscriben la investigación y sus resultados en una tradición y constatación. Después de una revolución pionera que tuvo mucho de agraria, era casi inevitable que en México existiera una larga y vigorosa tradición

Profesorainvestigadora del CUCSH. Universidad de Guadalajara. de estudio y reflexión acerca del papel del campo y los campesinos en el desarrollo nacional. No voy a repetir lo

Kirsten Appendini y Gabriela Torres-Mazuera (eds.) (2008), ¿Ruralidad sin agricultura? El Colegio de México, 255 pp. 
que todos aprendimos de las investigaciones, reflexiones, debates y polémicas entre Ángel Palerm, Arturo Warman, Cynthia Hewitt de Alcántara, Luisa Paré, Roger Bartra y tantos más en torno al tema. Esas forman parte de la historia de la antropología y los estudios rurales que hay que tener en cuenta pero no repetir.

Pero, como señalan Appendini y Torres-Mazuera, ya no es posible seguir pensando en términos tradicionales porque la relación entre el Estado mexicano y los campesinos ha cambiado de manera drástica. Las políticas estatales dirigidas al desarrollo agropecuario dan cuenta, una y otra vez, nos guste o no, de que los campesinos han sido marginados de tal manera que han dejado de formar parte del modelo de desarrollo nacional actual. En la economía global, competitiva, tecnologizada, los campesinos tradicionales han pasado a ser residuales. De protagonistas de la historia y el desarrollo nacionales han sido desplazados a un nuevo ámbito de la intervención estatal: las políticas compensatorias de combate a la pobreza. Para los campesinos ya no hay programas productivos de desarrollo agropecuario sino subsidios públicos de asistencia centrados en la educación, la salud y el consumo. Este es uno de los grandes escenarios donde se desenvuelve hoy la vida rural.

En segundo lugar, los estudios de este libro comparten otra gran constatación: que las actividades agropecuarias tradicionales, en especial, la agricultura, han dejado de ser el eje de la sobrevivencia de las familias en el campo. Entre 1970 y 2000 , dice Appendini, se observa la transición de las economías campesinas maiceras a las economías no agrícolas y la diversificación de los mercados locales de trabajo. El retiro de los subsidios y la competencia internacional han herido de muerte a las actividades agropecuarias tradicionales y de pequeña escala. De esa manera, las familias en el campo viven y sobreviven de una combinación de actividades, locales y extralocales, que se ubican sobre todo en los 
sectores comerciales y de servicio. Para las editoras, muchas de esas actividades están desligadas de la economía nacional y resultan muy similares a las actividades informales urbanas de las que tanto se habló en décadas anteriores.

Una tercera constatación es que los cambios han dado lugar a la emergencia de nuevos actores sociales en el campo. Como han mostrado muchos estudios en los últimos años, en la actualidad, las identidades y representaciones tradicionalmente asociadas al campo (ejidatarios, comuneros, asambleas) han comenzado a desdibujarse frente a la presencia de nuevos actores locales: las mujeres, los empresarios, los migrantes, los profesionistas, los pobres cuyos intereses y prácticas particulares han ampliado el espectro de quehaceres y maneras de vivir la ruralidad.

Esas tres constataciones sirven como hilos conductores de la pregunta central a la que buscan responder, desde diferentes ángulos, los once artículos que forman parte del libro: ¿Cómo han cambiado los modos de vida de la gente del campo en el contexto de la globalización?

La mayor parte de los trabajos que integran el libro se llevaron a cabo en tres pequeñas comunidades rurales de tres entidades del centro del país: el Estado de México, Querétaro y Morelos: Emilio Portes Gil, Boye y Barranca Honda. Se trata de comunidades rurales, como tantas, que fueron dotadas de tierras ejidales y comunales; que vivieron los impulsos de la revolución verde; que experimentaron enormes crecimientos demográficos hasta la década de 1970 que afectaron el tamaño y el uso de las parcelas; que observaron los cambios en los mercados regionales de trabajo; que vieron llegar la educación, los servicios públicos, la salud. Pero además, comparten otra peculiaridad: se trata de localidades que han pasado a formar parte de espacios metropolitanos y redes de ciudades y, por lo tanto, están expuestas a las dinámicas, demandas y tensiones de esa nueva espacialidad emergente. 
Las investigaciones generaron y recurrieron a un repertorio amplio de estrategias de investigación cuantitativas y cualitativas: información estadística, encuesta sociodemográfica y socioeconómica aplicada a 15-20\% de los hogares de las tres localidades principales de estudio, entrevistas abiertas, elaboración de "retratos", historias de vida, grupos focales. Los autores tuvieron siempre muy presentes las diferencias de género y generación. Cada autor recuperó información del acervo común y construyó su propio repertorio para la generación de información sobre temas específicos que, en varios casos, formaron parte de sus investigaciones de tesis.

Así, cada uno de los once capítulos explora una temática particular. Con todo, en términos generales los asuntos tratados pueden agruparse en cuatro grandes ejes analíticos: el papel y el sentido de la producción maicera; las características y consecuencias del nuevo orden laboral rural; el espacio regional y el sentido de la comunidad y los nuevos actores sociales en el campo.

Dos trabajos —el de Appendini, Cortés y Díaz Hinojosa (capítulo V) y el de Díaz Hinojosa (capítulo VI) — se dedican al estudio de un tema de debate internacional: las estrategias de seguridad alimentaria de los campesinos en cuanto al abasto del maíz. En ambos casos, los autores han elaborado categorías e indicadores específicos para cuatro comunidades de análisis. Los resultados dan cuenta de grandes divergencias entre las localidades en relación a los criterios de cantidad o calidad del maíz. Esto tiene que ver, por una parte, como bien destaca Díaz Hinojosa, con que el mercado ejerce una selección adversa, es decir, no distingue, a nivel de precios, la calidad de los maíces. Pero tiene que ver también con otras dos razones que parecen incidir en las opciones de las familias: la disponibilidad o no de tierra propia y, algo menos medible, pero que se filtra en la etno- 
grafía que es el cambio en las preferencias alimenticias que no abona, necesariamente, a favor de la calidad.

Hay que aceptar, aunque no nos guste ni sea políticamente correcto, que también hay cambios en ese sentido. El capítulo VII, de Hallie Eakin y Xochitl Guadarrama, que indaga en el impacto de las inundaciones en las pérdidas de las cosechas de maíz en la comunidad de Emilio Portes Gil apunta, como los dos capítulos antes mencionados, a que en la actualidad el maíz tiene múltiples significados que dependen, en buena medida, de la generación de la que se trate. Mientras más jóvenes, menor será la preocupación por mantener la producción maicera de autoabasto. El capítulo III, de Torres Mazuera, abunda y abona en ese mismo sentido. A partir de los retratos de cinco cohortes de familias en Emilio Portes Gil, la autora descubre que la valoración cultural y el orgullo de ser productor de maíz corresponden a las generaciones de más de sesenta años. En las cohortes de menores edades, asociadas a estrategias laborales muy diversificadas y deslocalizadas, la importancia de la producción de maíz es indudablemente menor.

De hecho, los cambios que han experimentado los mercados de trabajo rurales están muy presentes en varios capítulos del libro. En el capítulo II Kirsten Appendini deja sentadas las bases de la discusión: el cultivo de maíz se ha convertido en una actividad de subsistencia y complementareidad y el empleo rural se ha diversificado hacia otras actividades, por lo regular también a otros espacios. Hoy por hoy, la cuestión laboral, no agraria, es el tema de la reproducción económica de la vida en el campo. Hoy por hoy, lo que define a las economías rurales es la diversificación laboral.

La diversificación tiene tres características centrales: por una parte, se orienta sobre todo a actividades de comercio y servicios que - ha insistido Kirsten en trabajos previosson quehaceres informales, empleos marginales, de escaso 
crecimiento que tienen que ver más con la precariedad de las familias que con procesos económicos rentables y articulados al desarrollo económico. En segundo lugar, y esto es un hallazgo muy importante: las modalidades de la diversificación — comercial, de servicios, manufacturera — tienen cada vez menos que ver con las actividades locales y cada vez más con las características de los mercados regionales y microrregionales de trabajo. El espacio regional ha adquirido un papel central en la orientación de los flujos laborales de las pequeñas comunidades rurales. Esto se relaciona con una tercera constatación que surge del artículo de Appendini: en comunidades empobrecidas y mercados regionales de trabajo precarios, las economías locales dependen cada vez más de dos recursos: las transferencias externas públicas, es decir, los subsidios a la pobreza y las transferencias privadas, o sea, las remesas que envían los migrantes internos e internacionales a sus grupos domésticos.

El artículo de Adriana Larralde (capítulo IV) abunda y profundiza en el estudio de los mercados de trabajo a partir de dos comunidades rurales pero que forman parte de un entorno muy urbanizado del Estado de México. Basada en información censal de 2000 y en sus propias entrevistas, Larralde encuentra que la población sin trabajo en el agro y sin parcela, se desplaza a trabajar, de preferencia todos los días o sobre una base semanal, a diferentes espacios y actividades del entorno urbanizado. El destino laboral de los campesinos se orienta y define en una gran variedad de contextos laborales dispersos. Lo que se advierte es una enorme movilidad pendular cotidiana de los trabajadores a los que califica de commuting; personas que salen y regresan a las comunidades todos los días. Se trata de una práctica diferente de la vieja tradición de migración laboral temporal hacia la Ciudad de México que practicaron durante décadas muchas comunidades rurales del Estado de México. 
En la actualidad, la gente se desplaza, pero busca y puede regresar a sus comunidades de origen cada día.

De esta manera, el trabajo agropecuario, local y localizado, ha dejado de estructurar el mundo rural y con ello han perdido vigor dos instituciones que durante décadas controlaron las actividades laborales y normaron las relaciones y jerarquías de trabajo en las comunidades: la familia y el ejido. El trabajo se ha deslocalizado y el mundo laboral se ha vuelto heterogéneo y cambiante para la gente del campo. En esta situación, el capítulo de Larralde, reitera una constatación que está presente en varios capítulos del libro: el pueblo se ha convertido en un espacio eminentemente residencial. Los retratos que elaboró Torres Mazuera (capítulo III) dan cuenta de las transiciones laborales de las familias donde se aprecia el decrecimiento de los quehaceres agropecuarios, el incremento de la diversificación de empleos y actividades fuera de las comunidades que están basadas en ingresos salariales.

De hecho, esa es quizá la mayor aportación de este libro: la constatación de que la tierra ha dejado de tener valor y sentido como espacio para la producción agropecuaria y ha cobrado una enorme relevancia como ámbito residencial. Este cambio aparece mencionado en el capítulo de Kirsten Appendini pero ha sido retomado como tema y argumento central del capítulo de Gabriela Torres Mazuera. La autora da cuenta, por una parte, de la urbanización de la comunidad en términos de servicios y el surgimiento de barrios en antiguas áreas de cultivo. Los retratos muestran, generación tras generación, la transformación laboral y cómo este fenómeno ha modificado y resignificado el valor de la tierra como patrimonio y como lugar de residencia de trabajadores deslocalizados. Esta resignificación de la casa y la comunidad como espacios residenciales, no productivos, está también presente en el capítulo de Eiken y Guadarrama. 
Las tierras inundables han entrado al mercado de tierras, pero para ampliar la zona urbana de la comunidad.

Los capítulos VIII, de Christian Muñoz y XI de Gabriela Torres Mazuera, son muy explícitos al respecto. En Boye y La Fuente, así como en EGP se advierte esa gran transición: los sentidos, intereses y prácticas asociadas a los procesos de herencia y titulación de predios tienen que ver, en gran medida, con la demanda de las nuevas generaciones de suelo para fincar casas, no de parcelas para producir. Muñoz descubre que la diversificación regional del empleo ha permitido reducir quizá la migración a larga distancia que acarreaba el no ser heredero de tierras, pero ha incrementado el número de interesados en disponer de un solar para construir una casa, lo que ha intensificado la demanda y el precio de los predios susceptibles de ser urbanizados. Lo dice Gabriela Torres Mazuera de manera muy clara. El pueblo se ha convertido en un lugar de residencia donde las parejas buscan tener una casa propia e independiente, pero en un entorno que les permite disfrutar de las ventajas de un lugar seguro y aprovechar las redes familiares de apoyo para la crianza de los hijos cuando ellos salen a trabajar. Además, señala la autora, la comunidad se ha convertido en un espacio idóneo y factible donde los jóvenes, sobre todo, pueden incursionar en escenarios nuevos como la participación política.

Y ese es el otro gran tema que está presente en los capítulos de este libro: la diversificación de los actores locales. Como señalan Torres Mazuera y Muñoz, la diversificación espacial del trabajo ha reducido el poder de las instancias tradicionales de poder en el campo asociadas a la tenencia de la tierra y la producción agropecuaria: el ejido, los ejidatarios, los comuneros que eran los poseedores de la tierra $\mathrm{y}$, muchas veces, los gestores y representantes políticos de las comunidades. En ese sentido, puede decirse que la titulación individual de predios que generó la aplicación 
de Procede terminó de afectar esos dos últimos reductos de poder jerárquico tradicional en el campo que tanto se confundían: las autoridades paterna y ejidal.

Hoy en día, como señala Torres Mazuera, la educación, la participación, el acceso al consumo y la edad son marcadores de la creciente heterogeneidad que se observa en las comunidades rurales. Frente a la pérdida de poder de los actores y representaciones tradicionales del campo, han comenzado a emerger nuevos actores, nuevos intereses, nuevas posibilidades: las mujeres, los profesionistas, nuevos políticos; el Estado, por su parte, ha construido también su imagen y definido sus nuevos interlocutores en el campo: los pobres. El estudio pormenorizado acerca de la presencia $\mathrm{y}$, sobre todo, la incidencia en términos de significados y prácticas sociales, de esos nuevos actores locales de cuya existencia e intereses locales dan cuenta los capítulos de este libro es una vigorosa y sugerente línea de investigación sobre el mundo rural.

El capítulo IX, de Kirsten Appendini y Marcelo de Luca incide en la discusión acerca de si los cambios económicos, laborales y migratorios han acarreado o no procesos de empoderamiento de las mujeres. En éste, como en muchos otros estudios, no hay una conclusión definitiva. En este caso, puede tener que ver con una cuestión metodológica. En contextos rurales, donde la gente se conoce y reconoce y donde los chismes corren como la humedad, quizá los grupos focales no sean una buena estrategia para generar información sobre cambios, menos aún sobre los cambios femeninos vistos desde la perspectiva de las propias mujeres. Mi impresión es que esa técnica, en este tipo de contextos, tiende a reiterar las normas sociales y a canonizar los esquemas más tradicionales y esperados del comportamiento femenino. Otros trabajos, con otras metodologías, han dado cuenta de fenómenos, tensiones, situaciones y búsquedas femeninas que apuntan y descubren el cambio, 
no sin contradicciones y tensiones, que ha significado la emigración cada vez más definitiva de los padres, maridos, hermanos de las comunidades rurales.

El capítulo X, de Ivonne Vizcarra y Xóchitl Guadarrama puede ser visto también como un estudio de actores locales construidos desde el Estado. Para los sucesivos gobiernos de los últimos años, los campesinos son los principales pobres del país: allí es más fácil localizarlos, identificarlos, atenderlos, evaluar y elaborar cuentas alegres acerca del éxito de los programas Progresa y Oportunidades. Lo que muestran Vizcarra y Guadarrama, a partir de su estudio en cinco comunidades mazahuas del Estado de México, son las profundas fisuras familiares y sociales que ha generado la selección de los beneficiarios y la aplicación de los programas. ¿Quiénes son los pobres? Ahora todos tienen que mostrar que lo son, más que los otros de ser posible, en vez de tratar de salir de la pobreza. Los chismes, desacuerdos, incomprensión, quejas se han convertido en moneda corriente al interior de las comunidades, entre las mujeres. En un contexto marcado por la emigración definitiva de los hombres - ausencias de cinco a quince años no pueden ser caracterizadas de otro modo- lo que se advierte es que las mujeres han tenido que hacerse cargo no sólo de los hogares y los compromisos con la educación y salud sus hijos sino también de las obligaciones colaterales, formales e informales, legales y extralegales, que cada día se le suman a los programas. La ayuda a la pobreza, frente a la falta de opciones laborales locales y la ausencia de padres, hijos, esposos y hermanos, se ha vuelto indispensable pero la tensión social se ha vuelto, en muchos casos, irrespirable. Y eso abona al no regreso. El capítulo de Vizcarra y Guadarrama da cuenta de la mirada, otra vez unilateral, que ha construido el Estado respecto al mundo rural: del viejo modelo que sólo los entendía como productores agrícolas al esquema actual que sólo los concibe o percibe como pobres. 
Sin embargo, como muestran los once capítulos que forman este libro, el mundo rural ha experimentado cambios económicos, laborales, sociales y culturales drásticos: desaparición de la agricultura como eje de la economía rural local; diversificación de las actividades económicas y el empleo; la relevancia, como nunca antes, de los contextos regionales para las opciones locales; la migración definitiva a Estados Unidos; el valor inmobiliario, patrimonial, residencial de las tierras ejidales y comunales; la proliferación de actores sociales con intereses y prácticas novedosas y divergentes que borran las diferencias tradicionales entre el campo y la ciudad. En este ambiente de cambio social, los actores sociales han reivindicado, redefinido y resignificado el interés, los motivos, la voluntad, el sentido de permanecer en las comunidades. Aunque ya no sea un espacio agrícola.

Esa es, me parece, la nueva ruralidad que se anuncia desde el título: sin agricultura, pero quizá, aunque no en todos los casos, un lugar donde vivir y confrontar la deslocalización del trabajo; la separación indefinida pero también la difícil recreación de los derechos, los deberes y los afectos. Pero para entender y seguir los argumentos de los autores hay que leer con cuidado este flamante libro que no debe, por ningún motivo, pasar inadvertido para los viejos pero sobre todo para los nuevos estudiosos del mundo rural mexicano. 8 